Meningitis is common in neurosarcoidosis. $^{2,3}$ The CSF always exhibits lymphocytic pleiocytosis, the lowest proportion of lymphocytes reported being $68 \%{ }^{2}$ A low glucose level is also usual, the lowest CSF level of glucose reported being $18 \mathrm{mg} / \mathrm{dl}^{3}{ }^{3}$ In our case, lymphocytes were not predominant, the polymorph reaction was strong, and the level of CSF glucose was the lowest ever reported. Consequently, neurosarcoidosis must be added to the list of aetiologies of meningitis with neutrophilic pleiocytosis.

T HANSLIK J-C BOULARD L MOULONGUET-DOLERIS J PRINSEAU A BAGLIN

Service de Médecine Interne-Néphrologie, Hôpital Ambroise Paré, Université René Descartes,

9 av Charles de Gaulle, 92104 Boulogne, Cedex, France

1 Brown MM, Thompson AJ, Wedicha JA, Swash M. Sarcoidosis presenting with stroke. Stroke 1989; 20: 400-5.

2 Chapelon C, Ziza JM, Pietta JC, et al. Neurosarcoidosis: signs, course and treatment in 35 coidosis: signs, course and treatment in

3 Oksanen V. Neurosarcoidosis: clinical presentation and course in 50 patients. Acta Neurol tion and course in 50 pand 1986, 73: 283-90.
Scan

\section{Appraisal of self-learning}

Sir,

May I through your columns ask your readers for information about appraisal of selflearning?

As a general practitioner tutor I am well aware that individuals have different learning styles and motivations. I therefore feel that a good part of my task is to ensure that my registrar (trainee) develops the necessary skills and motivation for future self-learning.

Though most of my 'training' is now demand-led I wish to develop skills to monitor the development of self-education in my registrar. Can colleagues direct me to relevant papers and medline fields?

MB TAYLOR

Bateman Centre for Postgraduate Medical Studies, Birch Hill Hospital, Rochdale, Lancs OL12 9QB, UK

\section{Prevalence of diabetes in elderly patients with pacemakers}

Sir,

Smith et al, have discussed coronary heart disease, valvular heart disease, bradycardia and heart failure in the elderly patient. ${ }^{1}$ In one study, $82 \%$ of pacemaker implants were in patients aged over 65 years. ${ }^{2}$ Indications include syncope associated with complete heart block or sinus arrest, symptomatic sick sinus syndrome and symptomatic incomplete atrioventricular block. More debatable is the choice of pacemaker. ${ }^{\prime}$

Diabetes is a major risk factor for the development of coronary heart disease. ${ }^{3}$ Diabetics have increased rates of heart block following a myocardial infarction ${ }^{4}$ and right bundle branch block is more common in the diabetic outpatient population. ${ }^{5}$ We have assessed whether diabetics aged over 65 are

\section{Summary/learning points \\ - $8-11 \%$ of patients undergoing permanent pacemaker insertion may be diabetic}

more likely to need permanent cardiac pacemaker insertion. Patients who had undergone permanent pacemaker insertion were identified using hospital activity analysis data and ward admission books and case notes. Data for the reference population was obtained from a previous survey. ${ }^{6} \mathrm{~A}$ total of 542 patients were identified, of whom $11.07 \%$ were diabetic. In our control group $8.25 \%$ were diabetic. This gave a relative risk of 1.34 (p<0.01, 95\% confidence interval 1.25-1.44).

This result is an underestimate of the true relative risk for two reasons: the hospital activity analysis coding for diabetes is not $100 \%$ complete and so patients with diabetes were missed. Also, the non-diabetic group undergoing pacing are an unscreened group and it would be expected that some of them will be undiagnosed diabetics. It has been shown that the prevalence of elderly undiagnosed diabetics in the community is $3.3 \%{ }^{6}$ The aetiology of this excess risk is uncertain, although it has been suggested that there is a microangiopathic effect. ${ }^{5}$ It has also been shown in experimental diabetic animals that there is increased cholinergic sensitivity ${ }^{7}$ and this may have an effect on cardiac conduction. The aetiology is likely to be multifactorial and more research is needed to establish the relative contributions of these factors.

JT LEAR IG LAWRENCE AC BURDEN Department of Medicine, Leicester General Hospital Gwendolen Road

Leicester LE5 4PW, UK

1 Smith E, Powell H, Hastie IR. Coronary artery disease, valvular heart disease, bradycardia and heart failure. Postgrad Med f 1995; 71: 346-53.

2 de Belder MA, Linker NJ, Jones S, et al. Cost implications of the British pacing and electrophysiology group's recommendations for pacphysiology group's recommen

3 Kannel BW, McGee DL. Diabetes and cardioKannel BW, McGee DL. Diabetes and cardio-
vascular disease. The Framingham study. vascular disease. The Fram

4 Malmberg K, Ryden L. Myocardial infarction in patients with diabetes mellitus. Eur Heart $\mathcal{F}$ 1988; 9: 259-64.

5 Blandford RL, Burden AC. Abnormalities of cardiac conduction in diabetes. $B M \mathcal{F} 1984 ; 289$; 1659.

6 Croxson SCM, Burden AC, Bodington M, et al. The prevalence of diabetes in elderly people. Diabetic Med 1991; 8: 28-31.

7 Carrier GO, Edwards AD, Arousta RS. Cholinergic supersensitivity and decreased number of muscarinic receptors in atria from number of muscarinic receptors in atria from 1984; 16: 963-5.

\section{Glucose-6-phosphate dehydrogenase deficiency}

Sir,

We read the recent excellent review of glucose-6-phosphate dehydrogenase (G-6PD) deficiency by Mehta ${ }^{1}$ with great interest. Based on experience in Israel, we do not, however, concur with his statement that
'Kernicterus has been described in all population groups'. While G-6-PD deficiency is prevalent among some subsets of Sephardic Jews, neonatal jaundice associated with the condition in this population is milder than that observed in some other countries. In the early $1960 \mathrm{~s}$, before the advent of phototherapy, and at the same point in time as reports of kernicterus emanated from Greece, Szeinberg et $a l^{2}$ were unable to document any cases of kernicterus attributable to this condition in an Israeli high-risk population group. Two subsequent studies ${ }^{3,4}$ demonstrated a high incidence of neonatal jaundice in G-6PD-deficient neonates, but with a low rate of exchange transfusion. No cases of kernicterus were encountered in either of these studies. The overwhelming majority of our cases respond to phototherapy, which we commence when serum bilirubin levels exceed $250 \mu \mathrm{mol} / \mathrm{l}$.

Clearly, in different population groups, environmental or genetic factors appear to interact with G-6-PD deficiency to either dampen or exacerbate the jaundice. Sephardic Jewish G-6-PD deficient neonates appear to be at an advantage in this respect, over their counterparts in other ethnic groups.

MICHAEL KAPLAN CATHY HAMMERMAN Department of Neonatology, Shaare Zedek Medical Centre and Hadassah Medical School of the Hebrew University, ferusalem, Israel

1 Mehta AB. Glucose-6-phosphate dehydrogenase deficiency. Postgrad Med $\mathcal{F}$ 1994; 70: $871-7$.

2 Szeinberg A, Oliver M, Schmidt R, Adam A, Sheba C. Glucose-6-phosphate deficiency and hemolytic disease of the newborn in Israel. Arch Dis Child 1963; 38: 23-8.

3 Milbauer B, Peled N, Svirsky S. Neonatal hyperbilirubinemia and glucose-6-phosphate hyperbilirubinemia and glucose-6-phosphate
dehydrogenase deficiency. Isr ₹ Med Sci 1973; 9: 1547-52.

4 Kaplan M, Abramov A. Neonatal hyperbilirubinemia associated with glucose-6phosphate dehydrogenase deficiency in Sephardic-Jewish infants: incidence, severity and the effect of phototherapy. Pediatrics 1992; 90: $401-5$.

\section{Gallstone ileus: an old role for abdominal 'hand' scanning}

Sir,

I was surprised that the 69 -year-old patient reported by Seal and colleagues ${ }^{1}$ spent 14 days undergoing investigations before eventual surgery for gallstone ileus, and was in hospital for all of 10 weeks. Her extensive investigation included abdominal ultrasonography, double contrast barium enema, gastroscopy and isotope bone scintigraphy before an abdominal computer tomography (CT) scan yielded the correct diagnosis. Although this makes an interesting case report, it illustrates how excessive reliance on investigations may sometimes fail to advance the diagnosis, incur needless costs, prolong hospital stay and delay definitive treatment. The diagnosis could have been made earlier by the timely application of the 'hand' scan.

Features of small bowel obstruction associated with a palpable mass in the right iliac fossa in an elderly patient with anaemia and weight loss is sufficient indication for laparotomy as soon as the patient is deemed fit for surgery. Further investigation is unlikely 
to contribute significantly, and will not alter the need for surgery. Laparotomy in this case would have been both diagnostic and therapeutic. Even in this technological age, we should not forget that the old fashioned 'hand' scan at laparotomy can be an appropriate early investigation.

R HUTCHINSON Good Hope Hospital, Rectory Road, Sutton Coldfield, West Midlands B75 7RR, UK

1 Seal ECJ, Creagh MF, Finch PJ. Gallstone ileus: a new role for abdominal computer tomography. Postgrad Med $₹$ 1995; 71: 313-5.

\section{The changing context of under- graduate medical education}

Sir,

Working in a district general hospital linked to a teaching hospital we have a constant turnover of clinical medical students attached to our unit. We were therefore interested in the article by Parsell and Bligh ${ }^{1}$ discussing possible approaches to undergraduate education. They suggested a core curriculum with less factual information than the present system and more problem-based learning. In our experience, the latter has been a part of ward-based clinical teaching for some time but requires an adequate background knowledge to be effective.

At the end of their attachment to our unit each student is examined. This involves clinical cases and a separate 'spot' exam consisting of electrocardiograms (ECGs), Xrays and data interpretation. We recently analysed the last six months exams from 40 junior (3rd year) and 15 senior (4th or 5th year) students. In the ECG section $85 \%$ correctly recognised an acute myocardial infarction, $76 \%$ correctly stated whether the axis was left, right or normal, $76 \%$ correctly described the rhythm (sinus) and $51 \%$ were able to calculate the heart rate.

We are all able to remember facts drummed into us at medical school which are of no relevance to the practice of clinical medicine and strongly support the efforts of those trying to improve the undergraduate educa- tion process. The differences found between our students' abilities to recognise an acute myocardial infarction and to calculate heart rate suggests more emphasis needs to be placed on the core knowledge which we all try to work upon. Rather than adding to such a syllabus the problem will be what to leave out. The use of an objective, structured, clinical examination would seem a sensible way of ensuring an adequate core knowledge as well as more detailed problem-based knowledge. If not, pattern recognition of a myocardial infarction but no concept of other variations may become the norm.

$$
\begin{array}{r}
\text { K SHOTLIFFE } \\
\text { A BLIGHT } \\
\text { V SAXENA } \\
\text { Diabetes Centre, } \\
\text { St Helier Hospital, } \\
\text { Wrythe Lane, } \\
\text { Carshalton, Surrey, UK }
\end{array}
$$

1 Parsell GJ, Bligh J. The changing context of undergraduate medical education. Postgrad Med f 1995; 71: 397-403. 